\title{
Factors affecting uptake of $\geq 3$ doses of Sulfadoxine-Pyrimethamine for malaria prevention in pregnancy in selected health facilities, Arusha region, Tanzania
}

Witness Mkalukwatage Mchwampaka ${ }^{1 *}$ (D), Donath Tarimo², Frank Chacky ${ }^{3}$, Ahmed Mohamed ${ }^{4}$, Rogath Kishimba ${ }^{4,5}$ and Angela Samwel ${ }^{4}$

\begin{abstract}
Background: Tanzania adopted the revised World Health Organization policy in 2013 recommending a minimum of $\geq 3$ doses of Intermittent Preventive Treatment during pregnancy with Sulfadoxine-Pyrimethamine (IPTp-SP) to protect against malaria. A study in Tanzania in 2014 reported low (9\%) uptake. We investigated health workers knowledge about IPTp-SP and factors that influenced uptake of $\geq 3$ doses of IPTP-SP among pregnant women.

Methods: We conducted a cross-sectional study in 2017 among post-delivery women and health care workers from nine randomly-selected public health facilities in three Districts of Arusha Region. Probability proportional to size methodology was used to determine number of participants per facility. We used a structured questionnaire to collect socio-demographic and obstetric data, information on doses of SP received, and knowledge of SP for IPTp. Health care workers were interviewed about their knowledge for IPTP- SP and challenges encountered in its uptake and use.

Results: We interviewed 556 persons (median age 26 years, range $16-42$ years) with the response rate of $99.3 \%$. Of these, $484(87.1 \%)$ had $\geq 3$ Antenatal Care (ANC) visits. A total of 402 (72.3\%) were multigravida with 362 (65.1\%) having given birth at least once. Of the 556 participants, 219 (39.4\%) made their first ANC booking at < 17 weeks of pregnancy and 269 (48.4\%) had received $\geq 3$ doses of SP-IPTp. Factors associated with uptake of $>3$ doses of IPTpSP included having secondary or higher education [Adjusted Odds Ratio (AOR) $=1.6,95 \% \mathrm{Cl} 1.1-2.4$ ], attending $\geq 4$ ANC visits $[A O R=3.1,95 \% \mathrm{Cl} 2.1-4.6]$, having first antenatal booking at $<17$ weeks [AOR $=1.8,95 \% \mathrm{Cl} 1.4-2.3]$, and adequate knowledge on IPTp-SP [AOR =2.7, 95\%Cl 1.9-3.9]. Among 36 health care workers interviewed, 29(80.6\%) had adequate knowledge about IPTp-SP. SP was available in seven (87.5\%) of the visited health facilities and was administered under Direct Observed Therapy (DOT) in six (75\%) facilities. Health care workers reported that stock outs of SP was a challenge.

Conclusions: Fewer than half of the women interviewed reported uptake of $\geq 3$ doses of IPTp-SP. That is below the Tanzania national target of $80 \%$. Making $\geq 4$ ANC visits, having secondary or higher education, making an early first ANC visit and having adequate knowledge on IPTp-SP promoted uptake of $>3$ doses. Further qualitative studies are needed to explore factors that might contribute to low uptake of SP.
\end{abstract}

Keywords: IPTp-SP uptake, Malaria prevention, Tanzania

\footnotetext{
* Correspondence: mywitness20@yahoo.com

${ }^{1}$ Mount Meru Regional Referral Hospital (MMRRH), Preventive Section, P.O.

Box 3010, Arusha, Tanzania

Full list of author information is available at the end of the article
}

(c) The Author(s). 2019 Open Access This article is distributed under the terms of the Creative Commons Attribution 4.0 International License (http://creativecommons.org/licenses/by/4.0/), which permits unrestricted use, distribution, and reproduction in any medium, provided you give appropriate credit to the original author(s) and the source, provide a link to the Creative Commons license, and indicate if changes were made. The Creative Commons Public Domain Dedication waiver (http://creativecommons.org/publicdomain/zero/1.0/) applies to the data made available in this article, unless otherwise stated. 


\section{Background}

Malaria infection during pregnancy is caused chiefly by Plasmodium falciparum, the most common malaria species in Africa [1]. Approximately fifty million women become pregnant in malaria-endemic areas each year globally, half of whom are in sub-Saharan Africa, where malaria transmission is intense and perennial [2-4]. An estimated 10,000 women and 200,000 of their infants die each year as a result of malaria infection during pregnancy, and half of these are due to severe malarial anaemia in mothers and low birth weight new-borns [5].

Recent trials in Sub-Saharan Africa, including Tanzania, have shown that uptake of $\geq 3$ doses of Intermittent Preventive Treatment in pregnancy with Sulfadoxine Pyrimethamine (IPTp-SP) is superior to the previously recommended $\geq 2$ doses. IPTp-SP should be delivered at each scheduled Antenatal Care (ANC) visit (except during the first trimester) and doses should be given at least 1 month apart $[6,7]$. The increased doses are associated with less placenta malaria parasitaemia, higher birth weight, and increased protection of pregnant women against malaria infection [8-10]. As a result the World health Organization (WHO) now recommends use of $\geq 3$ doses of IPTp-SP in the 2nd and 3rd trimesters of pregnancy [11].

Since the adoption of this recommendation in 2013 in Tanzania, few studies have focused on SP uptake and determinants of $\geq 3$ doses of IPTp-SP. A study in Mozambique revealed uptake of $\geq 3$ doses of SP to be low (43.6\%) [12], while a study in Tanzania revealed even lower uptake (9\%) [10]. Facility, provider, and client factors have been shown to be associated with uptake of $\geq 2$ doses of SP for IPTp in Sub-Saharan Africa [13, 14]. However, it is not known if the same factors are also associated with the uptake of uptake of $\geq 3$ doses regimen. We investigated individual, health provider, and facility factors that influence uptake of $\geq 3$ doses of SP for IPTp.

\section{Methods}

\section{Study site}

Arusha region is in Northern Tanzania on the Kenyan border, encompassing savannah and part of the Great Rift Valley. It has a very low prevalence of malaria (< 1\%) [15]. The Region had a total population of 1.7 million in 2012, and has an area of $14,500 \mathrm{~m}^{2}$. Arusha was selected for the study as it was among the first three regions in which health care workers in different health facilities levels were trained on the new policy of administering the minimum of three doses of IPTp-SP during pregnancy.

\section{Study design}

A health facility-based cross-sectional study was conducted in nine selected Reproductive and Child Health $(\mathrm{RCH})$ clinics of public health facilities from Arusha
City, Meru, and Monduli councils. Public facilities were selected as they provide free delivery services, which result in most women in the region using them for deliveries.

\section{Study population}

The study population included post-delivery women residing in Arusha region. We also included health care workers providing $\mathrm{RCH}$ services.

\section{Inclusion criteria}

Any post-delivery woman in the postnatal ward in selected health facilities and had ANC card with her and any health care worker who was providing $\mathrm{RCH}$ services at $\mathrm{RCH}$ clinics in the selected study facilities were included. The data were collected for the period between April-May 2017.

\section{Exclusion criteria}

Any post-delivery woman in whom SP use was contraindicated (known to be allergic to sulphur, or HIVinfected and therefore using cotrimoxazole prophylaxis) or who had impaired communications or did not consent to be interviewed was excluded. Any health care worker who had impaired communications or did not consent to be interviewed was excluded from the study.

\section{Sample size and assumptions}

The sample size was obtained by using the general formula for calculating sample sizes for epidemiological studies [16].

Sample size $(n)=\frac{Z^{2} \mathrm{P}(100-\mathrm{P})}{\frac{\mathrm{A}^{2}}{\mathrm{E}}}$

Where

$\mathrm{n}=$ Sample size required

$\mathrm{z}=$ Standard normal deviation corresponding to $95 \%$ confidence interval which (1.96)

$\mathrm{P}=$ Proportional of pregnant women who received $\geq 3$ doses of IPTp-SP (estimated at $9 \%$ [10])

$£=$ Margin of error (estimated at 2.5\%)

A small margin of error was used due to the low rate of pregnant women receiving $\geq 3$-doses of IPTp-SP. The sample size was adjusted for non-response rate of $10 \%$, resulting in a total of 560 post-delivery women to be included. In addition, a total number of 36 health care workers were interviewed.

\section{Sampling procedure}

We used a multistage sampling technique to select participants. In the first, stage, three districts were selected randomly from seven Districts Council of Arusha Region. In the second stage, nine public health facilities were selected from the listed Districts, including a District hospital and two health centres. We purposefully 
included district hospitals since they serve the largest number of ANC clients. The same criterion was used to identify health centres to be involved in the study. In the third stage, at the selected health facilities, convenience sampling was used to recruit participants for interviews. For health care workers, six workers (at the hospital level) and three health workers (at health centre level) from $\mathrm{RCH}$ were selected randomly by lottery.

\section{Data collection for post-delivery women}

Consenting post-delivery women at selected health facilities who met inclusion criteria were interviewed using a standardized structured questionnaire designed in English and translated into Swahili (Additional file 1: Questionnaire for post-delivery women). Data collected included sociodemographic, individual obstetric characteristics, and knowledge about IPTp-SP. A total of nine questions were used to assess knowledge. Providing a correct response to at least six questions was categorized as adequate knowledge. ANC cards were used to crosscheck the gestational age (GA) attained, number of ANC visits, timing of ANC visits, number of IPTp-SP doses received, and GA at first ANC visit. In addition, they were used to exclude person using cotrimoxazole for prevention of Mother to Child Transmission (PMTCT), or those contraindicated to SP (those who were allergic to sulphur).

\section{Health care workers}

Consenting health care workers at selected health facilities were interviewed using a structured questionnaire designed in English and translated in Swahili (Additional file 2: Questionnaire for health staffs) at selected health facilities. Data collected included sociodemographic, knowledge of the new regimen, and challenge with its administration. A total of 12 questions were used to assess knowledge. Providing a correct response to at least eight questions was categorized as adequate knowledge.

\section{Observation checklist}

An observation checklist (Additional file 3: Observation checklist tool) was used to collect information on the presence of IPTp-SP health education materials such as posters and leaflets or health talks provided to patients before the start of the clinics, availability of water and cups for administering SP as Directly Observed Therapy (DOT), and availability of SP at the $\mathrm{RCH}$ clinic on the day of visit.

\section{Validity of data collection tools}

The validity of all questionnaires was assessed through several processes. Firstly, we used a "Back to Back" translation method where two teams were involved; the first team formulated the questionnaires in English language then translated them into Swahili language. The second team translated the Swahili questionnaires back to English. The two teams sat together and reviewed the two English versions identifying any distortion in the meaning then revised and approved the Swahili version. Secondly, the questionnaires, both English and Swahili versions received expert review during ethical clearance process and approved for data collection. Thirdly, the approved Swahili versions of the questionnaires were pretested in the field prior to conducting study to ensure clarity and flow of questionnaire and revised accordingly. Lastly, during analysis, we checked correlation of results from related questions to assess consistency in the responses.

\section{Data analysis}

Data were entered, cleaned, and analysed using Epi-Info version 3.5.1. Frequencies were used to summarize categorical variables and determine the proportion of postdelivery women who received three or more doses of SP for IPTp. Continuous variables were summarized by using measure of central tendencies (mean and median) and dispersion (range, standard deviation). The outcome/dependent variable (uptake of $\geq 3$ doses of SP for IPTp) was tested for association with predictors/independent variables; statistical significance was assessed by using the Chi-squared test, a $p$ value of $<0.05$ was set as a level of significance.

Multiple logistic regression analysis was performed to identify the significant predictors influencing uptake of $\geq 3$ doses of SP for IPTp while controlling for potential confounders. All variables with $p$-values $\leq 0.25$ in bivariate analysis were added into the multiple variable logistic regression model.

\section{Results}

\section{Background characteristics of respondents}

Of the 560 post-delivery women targeted, 556 (99.3\%) were interviewed. Arusha City contributed 226 (40.6\%). The median age of the interviewed post-delivery women was 26 years, (range, 16-42 years). Of the 556 respondents, 484 (87.1\%) had made $\geq 3$ ANC visits before delivery and 219 (39.4\%) booked their first ANC visit before 17 weeks of gestation (Table 1).

\section{Proportion of post-delivery women with uptake of $\geq 3$ doses of IPTp-SP}

In total, $269(48.4 \%)$ women received $\geq 3$ doses of SP for IPTp, 150 (27\%) received 2 doses, 110 (19.7\%) received one dose, and 27 (4.9\%) did not receive IPTp-SP despite attending at ANC at least twice. Of the interviewed women, 284 (51.1\%) reported not receiving SP at ANC in at least one of their routine ANC visits. Of these, 184 (65.8\%) reported it was due to unavailability of SP at the health facility. Of the $529(95.1 \%)$ women who received at least one dose of SP, 
Table 1 Demographic characteristics of post-delivery women

\begin{tabular}{|c|c|c|}
\hline Variable & Frequency (n) & Percentage (\%) \\
\hline \multicolumn{3}{|l|}{ Age group (years) } \\
\hline$<20$ & 49 & 8.8 \\
\hline $20-35$ & 456 & 82 \\
\hline $36+y r s$ & 51 & 9.2 \\
\hline \multicolumn{3}{|l|}{ Marital status } \\
\hline Married & 460 & 82.7 \\
\hline Single/widow & 77 & 13.9 \\
\hline Cohabiting & 19 & 3.4 \\
\hline \multicolumn{3}{|l|}{ Education level } \\
\hline No formal education & 42 & 7.6 \\
\hline Primary education & 273 & 49.1 \\
\hline Secondary education & 200 & 35.9 \\
\hline College/University & 41 & 7.4 \\
\hline \multicolumn{3}{|l|}{ Occupation } \\
\hline Farmer & 101 & 18.2 \\
\hline Housewife & 154 & 27.7 \\
\hline Petty business/self employed & 232 & 41.7 \\
\hline Employee (Private/public) & 69 & 12.4 \\
\hline \multicolumn{3}{|l|}{ Number of ANC visits } \\
\hline$<4$ & 243 & 43.7 \\
\hline$\geq 4$ & 313 & \\
\hline \multicolumn{3}{|l|}{ Gravidity } \\
\hline Prima gravida & 154 & 27.7 \\
\hline Multigravida & 402 & 72.3 \\
\hline \multicolumn{3}{|l|}{ Parity } \\
\hline 0 & 194 & 34.9 \\
\hline$\geq 1$ & 362 & 65.1 \\
\hline \multicolumn{3}{|l|}{ GA at first ANC visit } \\
\hline$<17$ weeks & 219 & 39.4 \\
\hline$\geq 17$ weeks & 337 & 60.6 \\
\hline \multicolumn{3}{|l|}{ Knowledge about IPTp-SP } \\
\hline Adequate & 273 & 49.1 \\
\hline Low & 283 & 50.9 \\
\hline \multicolumn{3}{|c|}{ Walking time to ANC facility in (min) } \\
\hline$\leq 30$ & 342 & 61.5 \\
\hline$>30$ & 214 & 38.5 \\
\hline
\end{tabular}

$149(28.1 \%)$ they reported that they did not swallow SP in front of the health care providers due to; absence of clean water or cups at the ANC clinics 74 (50\%), and being hungry $20(13.4 \%)$. Others did not mention the reasons but were given medication to take at home.

Factors influencing uptake of $\geq 3$ doses of IPTp-SP After adjusting for confounding variables, factors that remained significantly associated with the uptake of $\geq 3$ doses of SP for IPTp at the multivariate level included having secondary or higher education [Adjusted Odds Ratio $(\mathrm{AOR})=1.6,95 \% \mathrm{CI} 1.1-2.4]$, having visited an ANC at least four times $[\mathrm{AOR}=3.1,95 \% \mathrm{CI}, 2.1-4.6]$, having their first ANC visit at $<17$ gestation age $(\mathrm{GA})[\mathrm{AOR}=1.8$, 95\% CI 1.4-2.3], having adequate knowledge of IPTp-SP $[\mathrm{AOR}=2.7,95 \% \mathrm{CI}, 1.8-3.8]$, and having delivered at least once previously $[\mathrm{AOR}=1.7,95 \% \mathrm{CI} 1.2-2.6]$ (Table 2 ).

\section{Health worker interviews \\ Demographics characteristics}

A total of 36 health care workers were interviewed in nine health facilities. The mean age was 39.5 years (range, 19-60 years), and 35 (97.2\%) were female (Table 3). In total, 29 (80.6\%) had adequate knowledge of IPTp-SP. All the interviewed health workers reported administering SP at the ANC when it is was available

Table 2 Factors associated with uptake of $\geq 3$ doses of IPTp-SP by post-delivery women

\begin{tabular}{|c|c|c|}
\hline \multirow{2}{*}{$\begin{array}{l}\text { Variable } \\
\text { Age group (yrs.) }\end{array}$} & \multicolumn{2}{|c|}{ Crude OR (95\%Cl) Adjusted OR (95\%Cl) } \\
\hline & & \\
\hline$\geq 20$ & $1.8(1.15-2.89)$ & $1.1(0.60-1.83)$ \\
\hline$<20$ & Ref & Ref \\
\hline \multicolumn{3}{|l|}{ Education level } \\
\hline Secondary/college & $1.9(1.42-2.81)$ & $1.6(1.11-2.42)^{* *}$ \\
\hline Non/primary & Ref & Ref \\
\hline \multicolumn{3}{|l|}{ Occupation } \\
\hline Employed/self employed & $1.6(1.15-2.26)$ & $0.9(0.59-1.28)$ \\
\hline Farmer/housewife & Ref & Ref \\
\hline \multicolumn{3}{|l|}{ Number of ANC visit } \\
\hline$\geq 4$ & $3.5(2.48-5.04)$ & $3.1(2.12-4.62) * *$ \\
\hline$<4$ & Ref & Ref \\
\hline \multicolumn{3}{|l|}{ Gravidity } \\
\hline Prima gravida & $1.4(0.97-2.05)$ & $1.2(0.82-1.68)$ \\
\hline Multigravida & Ref & \\
\hline \multicolumn{3}{|l|}{ Parity } \\
\hline+1 & $1.6(1.09-2.21)$ & $1.7(1.22-2.68)^{* *}$ \\
\hline 0 & Ref & Ref \\
\hline \multicolumn{3}{|l|}{ GA at first ANC booking (wks.) } \\
\hline$<17$ & $1.6(1.15-2.29)$ & $1.8(1.42-2.30) * *$ \\
\hline$\geq 17$ & Ref & Ref \\
\hline
\end{tabular}

Knowledge of P. women on IPTP-SP

$\begin{array}{lll}\text { Adequate } & 3.1(2.17-4.33) & 2.7(1.85-3.89) * * \\ \text { Low } & \text { Ref } & \text { Ref }\end{array}$

Distance (walking time) to HF

$\begin{array}{lll}\leq 30 \mathrm{~min} & 1.5(1.07-2.14) & 1.3(0.88-1.89) \\ >30 \mathrm{~min} & \text { Ref } & \text { Ref }\end{array}$

"Statistically Significant $(p=<0.05)$ 
Table 3 Sociodemographic characteristics of Health Care Workers (HCW)

\begin{tabular}{lll}
\hline Variable & No of Health workers $n=36$ & Parentage \\
\hline District & 12 & 33.3 \\
Arusha City & 12 & 33.3 \\
Meru & 12 & 33.3 \\
Monduli & & \\
Level of Facility & 18 & 50 \\
Hospital & 18 & 50 \\
Health centre & & \\
Age in years & 11 & 30.6 \\
$<35$ & 25 & 69.4 \\
$>35$ & & \\
Sex & 35 & 97.2 \\
Female & 1 & 2.8 \\
Male & & \\
Title & 3 & 8.3 \\
Public health nurse & 5 & 13.9 \\
Enrolled nurse & 5 & 36.7 \\
Nurse assistant & 65.0 \\
Nurse Midwife & 13 & \\
Registered nurse & 9 & \\
\hline
\end{tabular}

and directing women to swallow it in front of health care provider.

Eight (88.9\%) of the nine selected health facilities underwent observation of health care workers using the checklist.

It was observed that health education regarding malaria and specifically SP for IPTp was given before the start of services. SP was available at seven (87.5\%) health facilities at the ANC; however, only three (37.5\%) had IPTp national protocols and two (25.0\%) had IPTp training manuals (Table 4). Five (62.5\%) health facilities had posters of IPTp or Malaria in Pregnancy (MIP) on their walls; however, some of these messages were in English and more scientific. Free, clean, and safe water was observed in seven $(87.5 \%)$ facilities; however, DOT was observed in only six (75.0\%). Forms for reporting adverse events associated with SP were available only in four $(50.0 \%)$ of the visited health facilities.

\section{The stated challenges of administering SP for IPTp}

Among the 36 interviewed health workers, 25 (69.4\%) reported running out of SP at the ANC clinic at some point during the past 3 months. Of these, 12 (48\%) reported that it occurred twice in the past 3 months, and nine $(36 \%)$ reported that it occurred once; the other four (16\%) could not recall. Pregnant women who missed medication on those days were asked to go and buy SP outside. Thirty-three (91.7\%) reported that their clinics supplied clean and safe water for pregnant women to swallow SP in front of the health care provider, and two $(8.3 \%)$ reported giving the medicine to pregnant women to swallow at home.

\section{Discussion}

Four years after adopting new recommendations nationwide to provide pregnant women with $\geq 3$ doses of SP for IPTp, actual uptake in the Arusha region of Tanzania was low. Fewer than half of the women interviewed received at least three doses. Independent factors that significantly influenced uptake of $\geq 3$ doses of IPTp-SP included having visited the ANC four or more times, having booked their first ANC visit $<17$ weeks of gestation, having adequate knowledge on IPTp-SP, having secondary or higher education, and having delivered at least once previously. Despite the fact that $\mathrm{a} \geq 3$ dose of SP for IPTp is superior to two doses, it is not fully utilized. Challenges to administration, including stock outs, may be partially related to the poor uptake.

The uptake of $\geq 3$ doses of IPTp-SP in the present study is lower $(48.4 \%)$ the national target of $80 \%$. However, it is higher than the uptake of $9 \%$ reported two years earlier in Tanzania [10]. Unavailability of SP at the health facility was reported in this study, has been reported in several previous studies that focused on twodose regimens [14, 17]. Stockouts present barriers to achieving the target and leave pregnant women unprotected from malaria. Practice of DOT in this study and other studies in Sub Saharan Africa [17] was found to be hampered by lack of knowledge among health care workers about the safety of SP on empty stomach as well as lack of availability of safe water and or cups.

Having made a first visit to an ANC early, as recommended by Tanzania Focused Antenatal Care (FANC), improved uptake of $\geq 3$ doses of SP for IPTp. This was also observed in studies in Zimbabwe and Tanzania that focused on two- dose regimen $[5,18]$. Similarly, having visited the ANC more than four times influenced uptake of $\geq 3$ of SP for IPTp. These findings are consistent with other studies conducted in Tanzania and West Africa $[3,5,15]$. This may be due to having an increased chance of receiving repetitive health education messages on ANC services, including the importance of SP, as well as increased opportunities to receive any missed doses at her multiple ANC visits.

Knowing about IPTp-SP was another independent factor associated with uptake of $\geq 3$ doses of SP for IPTp. This was also reported in studies in Tanzania and Ghana that focused on the two-dose regimen $[19,20]$. These suggest that if clients are knowledgeable of the importance of receiving SP, they are more likely to attend antenatal clinic to receive it. We also found that most women interviewed received information on IPTp from 
Table 4 Observation of practice of health workers on administering SP for IPTP

\begin{tabular}{lll}
\hline Variable & No.of facilities & Percentage (\%) \\
\hline Health talk given at ANC on day of visit & 8 & 100 \\
Health talk given that day included malaria in pregnancy & 8 & 100 \\
Health talk given that day included IPTp & 8 & 100 \\
Presence of request forms for ANC medicines including SP & 3 & 37.5 \\
Presence of posters of IPTp/MIP on the wall & 5 & 62.5 \\
Presence of ANC Report Book for daily summaries & 8 & 100 \\
SP given is recorded in ANC report Book for daily summaries & 8 & 100 \\
SP given is recorded in ANC cards of clients & 8 & 100 \\
SP available at ANC & 7 & 87.5 \\
Practice of DOT observed & 6 & 75 \\
Presence of Adverse Effects forms for SP & 4 \\
Presence of free, clean, safe water for DOT & 7 \\
Presence of safe, clean water for sale for DOT & 7 \\
Availability of IPTp National protocol & 0 & 87.5 \\
Availability of IPTp training manual & 3
\end{tabular}

the ANC clinics during their routine visits, and nearly all held positive perceptions of IPTp with SP for preventing malaria during pregnancy. This shows that pregnant women are equipped and therefore empowered with the correct information from the health care workers, which is in line with the FANC guidelines [21]. However, other means of delivering health education messages regarding IPTp should also be taken into accounts such as using the media (radio, television), leaflets, or others methods so that even pregnant women who were not planning to attend ANC early can find out the importance of attending to receive SP for IPTp.

We found that health care workers were knowledgeable about malaria prevention in pregnancy using SP. However, this knowledge might not be transferred to pregnant women who attend ANC clinics, as more than a half of post-delivery women had low knowledge about IPTp-SP. This may result in challenges accepting the drug when these pregnant women are issued SP. A study conducted in rural Nigeria showed that, despite of the pregnant women having heard about IPTp, 44 (40.4\%) women were afraid of taking drugs during pregnancy [22].

This study includes few limitations: the lack of generalizability to all health facilities as the study focused on public facilities. In addition, the questionnaire required some information from during the early stage of pregnancy that might have introduced recall bias. The ANC card was used to verify some of the key variables, which may have limited this type. Finally, although efforts were made to control for confounders at analyses stage, due to the crosssection design, unidentified confounders may still have affected the observations.

\section{Conclusion}

The uptake of $\geq 3$ doses of IPTp-SP in Arusha during 2017 was below the Tanzania national target of $80 \%$ coverage. In this study, the same factors that were previously shown to influence uptake of the two-dose regimen were found to influence uptake of $\geq 3$ doses of SP for IPTp. Having made $\geq 4$ ANC visits, having first visited the ANC at an early gestational age, having knowledge on IPTp-SP, having secondary or higher education, and having delivered at least once prior to the current delivery were significantly associated with the uptake of $\geq 3$ or more doses of SP for IPTp. Strategies to ensure constant availability of SP tablet at the RCH clinics along with a constant supply of clean water and cups at the health facilities should be emphasized. The IPT programme should ensure provision of standardized improved Information, Education and Communication (IEC) materials that contain clear and well understood information. This information should show not only the benefit of IPT, but also the number of doses and gestational age at which pregnant women should take this dose.

\section{Supplementary information}

Supplementary information accompanies this paper at https://doi.org/10. 1186/s12884-019-2592-0.

Additional file 1 Questionnaire for post-delivery women. The tool used to interview the post-delivery woman to assess factors affecting uptake of $>3$ doses of Sulfadoxine Pyrimethamine for Malaria prevention in Arūsha.

Additional file 2. Questionnaire for health facility staffs. This tool was used to collect information from health workers working in the department of Obstetrics and Gynaecology on their demographic characteristics, knowledge on the new regime of administering the 
minimum of three doses during pregnancy and challenges associated with administering IPT-SP.

Additional file 3. Observation checklist. This tool was used to collect information on the presence of IPTp-SP, health education materials such as posters and leaflets or health talks provided to patients before the start of the clinics, availability of water and cups for administering SP as directly observed therapy (DOT), and availability of SP at the RCH clinic on the day of visit.

\section{Abbreviation}

ANC: Antenatal Care; CHMT: Council Health Management Team; DOT: Directly Observed Therapy; FANC: Focused Antenatal Care; HCW: Health care workers; HF: Health facility; IPT: Intermittent Preventive Treatment; IPTp: Intermittent Preventive Treatment in pregnancy; ITN: Insecticide treated net; MoHCDGEC: Ministry of Health, Community Development, Gender, Elderly and Children; PMTCT: Prevention of Mother to Child Transmission; RCH: Reproductive and child health; RCH: Reproductive and Child Health; SP: Sulfadoxine- Pyrimethamine; TDHS: Tanzania Demographic and Health Survey; THMIS: Tanzania HIV/Malaria Indicator Survey; WHO: World Health Organization

\section{Acknowledgments}

These are directed to the Ministry of Health, Community Development, Gender, Elderly and Children (MoHCDGEC), Tanzania National Malaria and Control Programme (NMCP), the Region Administrative Secretary' (RAS) office of Arusha, the Regional Medical Officer (RMO) office of Arusha, the District Medical officers of Arusha City, Meru and Monduli, the Health facilities in charge of the visited facilities in Arusha Region, Muhimbili University of Health and Allied Sciences (MUHAS), Tanzania Field Epidemiology and Laboratory Training Programme (TFELTP) staff, Drs. Susan Rumisha and Julie Harris.

\section{Authors' contributions}

WMM Drafted research proposal, design study and research tools, provided technical expertise to the study data collection, supervised data entry processes, analysis and interpretation of findings, provided logistic and administrative issues, contributed to the manuscript development. DT Designed study and research tools, provided technical expertise to the study implementation, supervised the data entry process; analysis, and interpretation of the findings, contributed to the manuscript development; provided scientific expertise. FC Designed study and research tools, technical advisory the administrative issues, provided useful inputs to the manuscript. AM Reviewed study design and tools; provided technical expertise on the analysis and manuscript development. RK provided technical expertise on the analysis and manuscript development.AS Participated in developing Study design, study tools and fieldwork supervision, also played an important part in the manuscript development. All authors read and approved the final manuscripts.

\section{Funding}

This study was funded by Training Programs in Epidemiology and Public Health Interventions Network (TEPHINET). The funders had no role in the study design, data collection, analysis and interpretation of results, writing the manuscripts or the decision to submit for publication.

\section{Availability of data and materials}

The data used and/or analysed during the current study are available from the corresponding author on reasonable request.

\section{Ethics approval and consent to participate}

Ethical clearance and approval to conduct this study was granted by National Institute for Medical Research (NIMR) of Tanzania before conducting the study with reference no of NIMR/HQ/R.8a/vol.IX/2435.Consent for voluntary participation was sought from each participant signing the informed consent form after the study been explained to them.

\section{Consent for publication}

Not applicable.

\section{Competing interests}

The authors declare that they have no competing interests.

\section{Author details}

${ }^{1}$ Mount Meru Regional Referral Hospital (MMRRH), Preventive Section, P.O. Box 3010, Arusha, Tanzania. ${ }^{2}$ Muhimbili University of Health and Allied Sciences (MUHAS), Dar es Salaam, Tanzania. ${ }^{3}$ Tanzania National Malaria Control Programme (NMCP), Dar es Salaam, Tanzania. ${ }^{4}$ Tanzania Field Epidemiology and Laboratory Training Programme (TFELTP), Dar es Salaam, Tanzania. ${ }^{5}$ Ministry of Health, Community Development, Gender, Elderly and Children (MoHCDGEC), Dar es Salaam, Tanzania.

Received: 21 August 2018 Accepted: 11 November 2019

Published online: 27 November 2019

References

1. Hay SI, Guerra CA, Gething PW, Patil AP, Tatem AJ, Noor AM, et al. A world malaria map: plasmodium falciparum endemicity in 2007. PLoS Med. 2009;6(3):286.

2. Briand V, Cottrell G, Massougbodji A, Cot M. Intermittent preventive treatment for the prevention of malaria during pregnancy in high transmission areas. Malar J. 2007;6:160.

3. Vanga-Bosson HA, Coffie PA, Kanhon S, Sloan C, Kouakou F, Eholie SP, et al. Coverage of intermittent prevention treatment with sulphadoxinepyrimethamine among pregnant women and congenital malaria in Côte d'Ivoire. Malar J. 2011;10:105.

4. Dellicour S, Tatem AJ, Guerra CA, Snow RW, ter Kuile FO. Quantifying the number of pregnancies at risk of malaria in 2007: a demographic study. PLoS Med. 2010;7(1):e1000221.

5. Exavery A, Mbaruku G, Mbuyita S, Makemba A, Kinyonge IP, Kweka H. Factors affecting uptake of optimal doses of sulphadoxine-pyrimethamine for intermittent preventive treatment of malaria in pregnancy in six districts of Tanzania. Malar J. 2014;13(1):22 Available from: http://www.malariajournal. com/content/13/1/22

6. The United Republic of Tanzania Ministry of Health and social welfare. National Malaria Strategic Plan 2014-2020. National Malaria Control Programme, Dar es Salaam; 2014.

7. Tanzania Ministry of Health and Social Welfare. National Guidelines for Diagnosis and Treatment of Malaria:Malaria control series 11. National Malaria Control Programme, Dar es Salaam; 2006. p. 105.

8. Maiga OM, Kayentao K, Traoré BT, Djimde A, Traoré B, Traoré M, et al. Superiority of 3 over 2 doses of intermittent preventive treatment with sulfadoxine-pyrimethamine for the prevention of malaria during pregnancy in Mali: a randomized controlled trial. Clin Infect Dis. 2011;53(3):215-23.

9. Kayentao K, Kodio M, Newman RD, Maiga H, Doumtabe D, Ongoiba A, et al. Comparison of intermittent preventive treatment with chemoprophylaxis for the prevention of malaria during pregnancy in Mali. J Infect Dis. 2005; 191(1):109-16

10. Mpogoro FJ, Matovelo D, Dosani A, Ngallaba S, Mugono M, Mazigo HD. Uptake of intermittent preventive treatment with sulphadoxinepyrimethamine for malaria during pregnancy and pregnancy outcomes: a cross-sectional study in Geita district, North-Western Tanzania. Malar J. 2014;13: 455 Available from: http://www.ncbi.nlm.nih.gov/pmc/articles/PMC4256934/.

11. Access O. WHO Malaria Policy Advisory Committee and Secretariat. Malaria Policy Advisory Committee to the WHO: conclusions and recommendations of September 2012 meeting. Malaria J. 2012;11:424. Available from: http:// www.pubmedcentral.nih.gov/articlerender.fcgi?artid=3558335\&tool= pmcentrez\&rendertype=abstract

12. Brentlinger PE, Dgedge M, Correia MAC, Rojas AJB, Saúte F, Gimbel-Sherr $\mathrm{KH}$, et al. Intermittent preventive treatment of malaria during pregnancy in central Mozambique. Bull World Health Organ. 2007;85(11):873-9 Available from: http://www.ncbi.nlm.nih.gov/pmc/articles/PMC2636267/.

13. Hill J, Hoyt J, van Eijk AM, D'Mello-Guyett L, ter Kuile FO, Steketee R, et al. Factors affecting the delivery, access, and use of interventions to prevent malaria in pregnancy in sub-Saharan Africa: a systematic review and metaanalysis. PLoS Med. 2013;10(7):e1001488.

14. Anders K, Marchant T, Chambo P, Mapunda P, Reyburn H. Timing of intermittent preventive treatment for malaria during pregnancy and the implications of current policy on early uptake in north-East Tanzania. Malar J. 2008;7:79.

15. Tanzania Commission for AIDS (TACAIDS), Zanzibar AIDS Commission (ZAC) NB of S, (NBS), Office of the Chief Government Statistician (OCGS), and ICF 
International. Survey I. Tanzania HIV/AIDS and Malaria Indicator Survey 2011-12: Key Findings. Dar es Salaam. Tanzania: TACAIDS, ZAC, NBS, OCGS, and ICF International; 2013.

16. Lemeshow S, Hosmer DW, Klar J, Lwanga SK, World Health Organization. Adequacy of sample size in health studies. 1990.

17. Tarimo DS. Appraisal on the prevalence of malaria and anaemia in pregnancy and factors influencing uptake of intermittent preventive therapy with sulfadoxine-pyrimethamine in Kibaha district. Tanzania: East African Public Health Association; 2007.

18. Aaron E, Alvare T, Gracely EJ, Riviello R, Althoff A. Predictors of Linkage to Care for Newly Diagnosed HIV-Positive Adults. West J Emerg Med. 2015; 16(4):535-42 [cited 2016 Sep 30]. Available from: http://www. pubmedcentral.nih.gov/articlerender.fcgi?artid=4530911\&tool= pmcentrez\&rendertype=abstract.

19. Jeremiah M.Ngondi, Deus S.Ishengoma etal; Surveillance for sulfadoxinepyrimethamine resistant malaria parasites in the Lake and Southern Zones, Tanzania, using pooling and next general sequencing. Malaria Journal 16, Article number: 236 (2017)

20. Antwi GD. Factors influencing the uptake of intermittent preventive treatment of malaria in pregnancy in Bosomtwe district of Ghana. Kumasi: Nkrumah University of Science and Technology; 2010.

21. The United Republic of Tanzania Ministry of Health and Social Welfare. Focused Antenatal Care malaria and syphilis in pregnancy Learner 's Guide for ANC Service Providers and supervisors. Ministry of Health Social Welfare,Dar es Salaam; 2009. p. 85.

22. Akinleye SO, Falade CO, Ajayi IO. Knowledge and utilization of intermittent preventive treatment for malaria among pregnant women attending antenatal clinics in primary health care centers in rural southwest, Nigeria: a crosssectional study. BMC Pregnancy Childbirth. 2009;9(1):28 Available from: http:// bmcpregnancychildbirth.biomedcentral.com/articles/10.1186/1471-2393-9-28.

\section{Publisher's Note}

Springer Nature remains neutral with regard to jurisdictional claims in published maps and institutional affiliations.

Ready to submit your research? Choose BMC and benefit from:

- fast, convenient online submission

- thorough peer review by experienced researchers in your field

- rapid publication on acceptance

- support for research data, including large and complex data types

- gold Open Access which fosters wider collaboration and increased citations

- maximum visibility for your research: over $100 \mathrm{M}$ website views per year

At $\mathrm{BMC}$, research is always in progress.

Learn more biomedcentral.com/submissions 